\title{
LOSS AVERSION IS CONSISTENT WITH STOCK MARKET BEHAVIOR
}

\author{
Dr. Samih Antoine Azar \\ Full Professor \\ Faculty of Business Administration \& Economics \\ Haigazian University \\ Beirut, Lebanon \\ E-mail: samih.azar@haigazian.edu.lb
}

\begin{abstract}
The purpose of this paper is to verify that discrete statistical distributions of the US stock market are consistent with loss aversion. Loss aversion has the following tenets: an S-shaped valuation function, characterized by diminishing sensitivity, a loss aversion coefficient higher than +1 , probability weighting, and reference-dependence. Diminishing sensitivity implies that the exponent of the valuation function is between 0 and +1 . It is expected that this exponent be higher for losses. Probability weighting replaces objective with subjective probabilities. Loss aversion is indicated by a coefficient higher than +1 for the valuation of losses. There are three parameters: the two exponents of the valuation function, and the loss aversion coefficient. There is one non-linear equation: the certainty equivalence relation. The procedure is to fix two parameters and find the third parameter by solving the non-linear certainty equivalence equation, using the EXCEL spreadsheet. The program is repeated for more than one case about the fixed parameters, and by enriching the analysis with probability weighting. The calibrations executed point strongly to the conclusion that loss aversion is consistent with six discrete distributions of the first two moments of returns of the US stock markets. The calibration process provides for reasonable estimates of the key parameters of loss aversion. These estimates suggest a more pronounced diminishing sensitivity, and a higher than expected coefficient of loss aversion, especially when probability weighting is imposed.
\end{abstract}

Keywords: Stock Market Data, Behavioral Finance, Valuation Function, Loss Aversion Coefficient, Loss Aversion Exponents, Certainty Equivalence, Expected Utility, Probability Weighting.

JEL Classification Codes: G4, G1, E7.

\section{INTRODUCTION}

Loss aversion is at the heart of behavioral finance and behavioral economics. In this contemporary field of economic science, and unlike other specialties, at least five different Nobel Prize winners in economics were awarded the prestigious recognition of excellence. The story begins with Herbert Simon, a 1978 laureate, "for his pioneering research into the decisionmaking process within economic organizations", and his notions of bounded rationality and satisfying behavior. The second is Daniel Kahneman in 2002 "for having integrated insights from psychological research into economic science, especially concerning human judgment and decision-making under uncertainty". Kahneman developed his work, denominated prospect theory, with the help of Tversky, and both have pioneered the application of psychology to economics (Tversky \& Kahneman, 1974, 1981, 1986, 1991, 1992; Kahneman \& Tversky, 1979, 
1981, 2000).However Tversky was defunct when this Nobel Prize was awarded, and Nobel Prizes are not awarded posthumously. The third winner is Richard Thaler in 2017 for "his contributions to behavioral economics", some of which are in Camerer et al. (2011).

As a fundamental tenet of behavioral economics, loss aversion signifies that losses loom worse than gains. Other important tenets are probability weighting, the existence of a reference point for valuation purposes, and diminishing sensitivity to risky outcomes. Probability weighting identifies a dent between subjective and objective probabilities. The existence of a reference point implies that valuation must be in terms of gains and losses and not in terms of wealth outcomes. And diminishing sensitivity predicts that the elasticity of value relative to gains and to (absolute) losses is less than or equal to unity. For example, Angner (2016) has used the limiting case of unit elasticity for gains and losses for illustration purposes.

Harry Markowitz (1952), who posited that utility depends positively on the expected return, and not on wealth, and negatively on the variance of returns, ought to be considered as a precursor of behavioral finance. Markowitz is the fourth Nobel Prize co-winner in 1990 in this specialty. Finally Robert Shiller, a 2013 Nobel Prize co-winner, with his empirical study of financial markets, is not disconnected from the above literature, and has added the required applied and econometric façade to behavioral finance. Shiller has popularized his approach in Shiller (2000), and, with Akerlof, in Akerlof and Shiller (2009).

The fact that loss aversion is economically well-entrenched, and that it is well established in economic science, is no longer disputed. However, there is a need for more comprehensive research on the topic, and an opportunity to tackle competing and controversial issues like that of the Efficient Market Hypothesis (Fama, 1970, 1991), which was popularized by Malkiel (1996).

The major finding of this paper is that the calibration process of loss aversion, which is implemented on risky outcomes of the common stock market, is successful in producing reasonable, and theoretically valid, values for the third "free" parameter that is solved for. This should give impetus and momentum for the desirability of loss aversion as a key theoretical construct. Not only does loss aversion explain stock market statistics, but it applies also to complex outcomes, and not only to small games or fair games, as it was at first believed. Moreover the S-shaped valuation function, which is central to loss aversion, and which embodies its precepts, is strongly supported.

The paper is organized as follows. The following section, section 2 , is a survey of the literature. We will try in section 3to calibrate the three parameters of loss aversion, by taking into account, from the literature, the first two moments of the common stock market, which are converted into discrete probability distributions. This calibration necessitates the knowledge of two out of the three parameters in order to solve for the third parameter by optimization of the non-linear certainty equivalence relation of valuation. The fourth section is the applied calibration, and uses expected utility and is based on certainty equivalence. Four different prespecified sets for the two parameters, that are to be fixed, are utilized. The fifth section repeats the analysis by applying probability weighting, which is also at the centerpiece of loss aversion. The last section summarizes and concludes.

\section{SURVEY OF THE LITERATURE}

This survey will tackle two issues: (1) the methods used to test for loss aversion, and (2) the estimates in the literature of the parameters in the behavioral valuation function. The first issue will highlight the contribution of this paper to the existing literature, and the second will provide 
reassuring evidence that the results of this contribution are in line with those in the literature. We begin by the first issue.

Tversky and Kahneman (1992) use experimental data. Benartzi and Thaler (1995) use a piece-wise linear valuation function and study the stock market, and especially they measure the evaluation period of the portfolio held by investors. They find a period close to 12 months, which is reasonable. Abdellaoui et al. (2008) uses certainty equivalents for two outcome prospects. Our paper also uses certainty equivalents but the outcomes can reach seven. Tovar (2009) applies loss aversion to protected industries in trade policy, and to anti-trade, import-enhancement, policies, and finds evidence for diminishing sensitivity and loss aversion. Foellmi et al. (2019) model loss aversion in a macroeconomic setting and assume that the gains and the losses are the changes in aggregate consumption. They find evidence that risk aversion differs across countries for a broad set of OECD countries, and is quite generally higher than 1. They test whether loss aversion correlates with economic fundamentals and find that it is negatively related to both GDP and consumption per capita.

The main theoretical background is the valuation function, which is nothing else than the piece-wise utility function $U$, and this function represents the preferences of the individual over gains and losses $(X)$, the zero per cent level being the reference point:

$$
U=X^{\alpha} \quad \text { if } X \geq 0
$$

The restrictions for this valuation function are that $\alpha$ and $\sigma$ be positive and less than one, and that $\lambda>1$. The parameter $\lambda$ is designated as the loss aversion coefficient. In this function there are three parameters: $\alpha, \sigma$, and $\lambda$. Two of these three parameters must be specified to determine the third one from the certainty equivalence equation. In this regard, and for example, Tversky and Kahneman (1992) find a median exponent of 0.88 for $\alpha$ and $\sigma$, "in accord with diminishing sensitivity", and a median $\lambda$ of 2.25, "indicating pronounced loss aversion". The exponents $\alpha$ and $\sigma$ are sometimes taken to be not only equal but also to equal exactly 1, producing a piecewise linear valuation function. Such a function has been studied by Benartzi and Thaler (1995), and much more recently by Foellmi et al. (2019) for cross country differences in preferences. The phrase that is very often repeated in the literature is that the loss aversion coefficient $\lambda$ is around 2, making losses hurt twice as much as the pleasure from a similar gain (Camerer, 2005; Novemsky \& Kahneman, 2005; Paraschiv \& L'Harido, 2008; Tovar, 2009; Gal \& Rucker, 2018). However there is variation in the literature when experimental evidence is sought. For example Schmidt \& Traub (2002) find a mean value as low as 1.43, while Fishburn and Kochenberger (1979) find a median value as high as 4.8. See Abdellaoui et al. (2008) for median estimates between 2.24 and 3.01. Levy (2010) start the analysis by assuming an $\alpha=1$, and finds a point estimate of the loss aversion coefficient at 2.20, which is "very close to the value of $\lambda=2.25$ obtained by a completely different approach" (Levy, 2010:1019). His interval estimate is between 1.51 (for Denmark) and 3.61 (for Australia). In this paper, and using a still completely different approach from the literature, $\lambda$ is found to be very close to the above estimates. This is a reassuring result and points to the robustness and pervasiveness of the existence of the loss aversion coefficient $\lambda$ which is one of the main aims of this paper.

As for the estimates of $\alpha$ and $\sigma$, besides the study of Tversky and Kahneman (1992) which found both $\alpha$ and $\sigma$ equal to 0.88, Camerer and Ho (1994) find both $\alpha$ and $\sigma$ equal to 0.37, Wu and Gonzalez (1996) find both $\alpha$ and $\sigma$ equal to 0.52, Abdellaoui (2000) find an 
$\alpha$ of 0.89 and $a \sigma 0.92$, and Abdellaoui et al. (2005) find an $\alpha$ of 0.91 and $a \sigma 0.96$, Abdellaoui et al. (2007) find an $\alpha$ of 0.72 and $a \sigma 0.73$ while Abellaoui et al. (2008) find median estimates with an $\alpha$ of 0.86 and a $\sigma$ of 1.06. See Levy (2010). Prospect theory predicts that $\sigma$ be higher than $\alpha$. It must be mentioned that a $\sigma$ higher than 1 implies convexity, and if both $\alpha$ and $\sigma$ are higher than 1 the utility function becomes totally convex, and supports Markowitz's analysis.

Lately loss aversion has been challenged (Gal \& Rucker, 2018) and one of the originators of prospect theory, Kahneman, has talked about "boundaries" to loss aversion (Novemsky \& Kahneman, 2005). The issue at stake, which is whether loss aversion applies always versus whether it applies on balance, will not be dwelt upon in this paper.

\section{METHOD}

The certainty equivalence states that expected utility of risky outcomes to be equal to the utility of a certain equivalent gain. This certain gain is posited to be the risk-free interest rate. The latter is estimated to be $3.8 \%$ (Ross et al., 2002: 233). There remains to specify the risky outcomes. For this purpose the six economies, identified by Azar (2006), will do the job for generating six discrete probability distributions that have approximately an arithmetic mean of $13.3 \%$ and a standard deviation of $20.1 \%$, which are the first two statistical moments of a portfolio of common stocks, and this according also to Ross et al. (2002). See Table 1. For example the equation that should hold is the following for the third economy of Azar, which has four outcomes, each having an individual probability of 0.25 . The risky outcomes, for this economy of four states of nature, are respectively $35 \%, 25 \%, 10 \%$, and $-20 \%$. They produce a probability distribution of mean $12.5 \%$, and standard deviation of $20.77 \%$, figures that are very close to the actual ones. It is noticeable that we have been using objective probabilities, assuming away probability weighting, in order to stress on loss aversion. This initial shortcoming is addressed for later.

$$
0.25\left(0.35^{\alpha}\right)+0.25\left(0.25^{\alpha}\right)+0.25\left(0.1^{\alpha}\right)-0.25 \lambda\left(0.2^{\sigma}\right)=0.038^{\alpha}
$$

As another example the equation that should hold with the last economy is:

$$
\begin{aligned}
\left(\frac{1}{7}\right)\left(0.55^{\alpha}\right)+ & \left(\frac{1}{7}\right)\left(0.35^{\alpha}\right)+\left(\frac{1}{7}\right)\left(0.15^{\alpha}\right)+\left(\frac{1}{7}\right)\left(0.10^{\alpha}\right)+\left(\frac{1}{7}\right)\left(0.00^{\alpha}\right)-\lambda\left(\frac{1}{7}\right)\left(0.05^{\sigma}\right) \\
& -\lambda\left(\frac{1}{7}\right)\left(0.15^{\sigma}\right)=0.038^{\alpha}
\end{aligned}
$$

As mentioned above, these equations can only be solved if there is only one "free parameter". Two sets of restrictions are imposed. The first is to assume that $\alpha=\sigma$, and to specify three different values for $\lambda$, which are: $2.0,2.25$, and 2.5. And the second is to assume that $\sigma=1$, and specify the same three values for $\lambda(2.0,2.25$, and 2.50). The "free" parameter is $\alpha$ in both cases. This second case, and especially the assumption that $\sigma=1$, corresponds to the extreme case of loss aversion, and is theoretically plausible. In both sets of restrictions the free parameter, to be solved for, is $\alpha$ and the theoretical requirement on $\alpha$ is that $0<\alpha<1$. The parameter $\alpha$ is obtained by using the solver command in EXCEL to search for $\alpha$, granted that the above non-linear certainty equivalence function stands.

Additional simulations can be performed. This time it is the loss aversion coefficient $\lambda$ which is the free parameter. Two cases are posited. In the first case $\alpha=\sigma=0.88$, values that 
correspond to the estimates of Kahneman and Tversky (1992). And the second case is to assume that $\alpha=0.5$, and $\sigma=1$. The latter value for $\sigma$ corresponds to a linear valuation function for losses.

Finally, the analysis is repeated by inclusion of probability weighting, whereby the constant objective probabilities are replaced by subjective ones that are calculated according to a formulae derived in Kahneman and Tversky (1992).

\section{RESULTS WITHOUT PROBABILITY WEIGHTING}

In this section the probabilities of all outcomes are objective, depending on the number of states in each economy. The probabilities are assumed constant and the same for all outcomes pertaining to a given economy. The results are found in Tables 2, 3, and 4 . In Table 2 the free parameter is $\alpha$ and it is assumed that $\alpha=\sigma$. Three different cases are singled out. These are respectively for loss aversion coefficients $\lambda$ of 2.0,2.25, and 2.5, which are the usual coefficients from the literature. It is noticed that the higher the loss aversion coefficient is the higher is $\alpha$. For a $\lambda=2.0$, the average $\alpha$ is 0.714 , and the values for $\alpha$ range from 0.652 to 0.772 . For a $\lambda=$ 2.25 , the average $\alpha$ is 0.774 , and the values for $\alpha$ range from 0.692 to 0.817 . For a $\lambda=2.5$, the average $\alpha$ is 0.834 , and the values for $\alpha$ range from 0.731 to 0.893 . All estimates are less than +1 , and conform to expectations of diminishing sensitivity. Moreover these estimates are close but a bit lower than the estimate of Tversky and Kahneman (1992) of 0.88. We can conclude strongly that loss aversion explains relatively very well risky stock market return outcomes.

Insert Table 2 (Appendix B)

Table 3 presents the simulations under the assumptions that $\sigma=1$, and with the loss aversion coefficients $\lambda$ of 2.0,2.25, and 2.5, which are thesame values as above. The free parameter is again $\alpha$. It is expected that $\alpha$ be close to 0.5 . This is indeed the case.For a $\lambda=$ 2.0 , the average $\alpha$ is 0.3704 , and the values for $\alpha$ range from 0.3044 to 0.4449 . For a $\lambda=$ 2.25 , the average $\alpha$ is 0.3933 , and the values for $\alpha$ range from 0.3310 to 0.4694 . For a $\lambda=$ 2.5 , the average $\alpha$ is 0.4196 , and the values for $\alpha$ range from 0.3625 to 0.4974 . Although less than 0.5 theses values are nevertheless close to 0.5 . Again loss aversion explains very well risky stock market return outcomes. There is one discrepancy however. Next to the estimates of $\alpha$, in Table 3, is the starting value (SV) for each simulation. If the condition of this starting value is obeyed the model converges directly to the reported estimates of $\alpha$. If the starting value (SV) is higher than the one reported, then the program does not converge at first, and for still higher values of $\alpha$ the program converges to estimates of $\alpha$ that are higher than +1 . It is not known why this anomaly is present. Otherwise diminishing sensitivity readily explains risky stock market return outcomes.

\section{Insert Table 3 (Appendix C)}

Table 4 departs from Tables 2 and 3, in that the free parameter is $\lambda$. In the first case we posit that $\alpha=\sigma=0.88$, in conformity to Tversky and Kahneman (1992). And in the second case we posit that $\alpha=0.5$, and $\sigma=1$. For the first case the average value of $\lambda$ is 2.745 , and the values range between 2.247 and 3.517. And for the second case the average value of $\lambda$ is 3.071, and the values range between 2.522 and 3.476. In both cases the loss aversion coefficient is higher than 
+1 as expected by prospect theory. Hence loss aversion explains quite well the stock market return dynamics.

Insert Table 4 (Appendix D)

\section{RESULTS WITH PROBABILITY WEIGHTING}

In this section probability weighting is incorporated in the place of the objective probabilities. The implied subjective probabilities differ in case of gains and in case of losses. However they follow a general format (Tversky \& Kahneman, 1992). This format is:

$$
\pi=\frac{p^{\delta}}{\left(p^{\delta}+(1-p)^{\delta}\right)^{1 / \delta}}
$$

In this equation the parameter $\delta$ takes the value 0.61 for gains, i.e. for $X \geq 0$, and 0.69 for losses, i.e. for $X<0$. Table 5 presents the list of all probabilities objective and subjective, for gains and for losses, listed according to the respective economy considered for each calculation. If the objective probability is 1 then the subjective probability is also 1 , in conformity to the literature. This will enable a correct weighting of the utility of the certainty equivalent.

\section{Insert Table 5 (Appendix E)}

The computations carried out in Tables 2, 3, and 4, are repeated in Tables 6, 7, and 8, with the subjective probabilities replacing the objective ones. In Table 6 the free parameter is $\alpha$ and it is assumed that $\alpha=\sigma$, and that the loss aversion coefficients $\lambda$ can take the following three values: $2.0,2.25$, and 2.5 .

It is noticed that the higher the loss aversion coefficient is the higher is $\alpha$. There is one exception, however, in case of the economy A, and with a loss aversion coefficient of 2 . Another existing pattern is that the estimated $\alpha$ decreases with the economy. This may be due to the fact that the economies are listed by the number of states of nature, which is smallest for economy A and largest for economy F. Hence more probability weighting is effectuated by economy, going from $\mathrm{A}$ to $\mathrm{F}$. An additional existing pattern is that the higher the assumed coefficient for loss aversion, $\lambda$, the higher is the estimate of $\alpha$. For a $\lambda=2.0$, the average $\alpha$ is 0.658 , and the values for $\alpha$ range from 0.501 to 0.836 . For a $\lambda=2.25$, the average $\alpha$ is 0.708 , and the values for $\alpha$ range from 0.549 to 0.840 . For a $\lambda=2.5$, the average $\alpha$ is 0.787 , and the values for $\alpha$ range from 0.595 to 0.921 . All estimates are less than +1 , and conform to expectations of diminishing sensitivity. Moreover these estimates are close but a bit lower than the estimate of Tversky and Kahneman (1992) of 0.88. We can conclude strongly that loss aversion explains relatively very well risky stock market return outcomes even in case of probability weighting.

\section{Insert Table 6 (Appendix F)}

Table 7 presents the simulations under the assumptions that $\sigma=1$, and with loss aversion coefficients $\lambda$ of 2.0,2.25, and 2.5, the same values as above. The free parameter is again $\alpha$. It is expected that $\alpha$ be close to 0.5 . This is indeed the case. For a $\lambda=2.0$, the average $\alpha$ is 0.262 , and the values for $\alpha$ range from 0.101 to 0.557 . For a $\lambda=2.25$, the average $\alpha$ is 0.283 , and the values for $\alpha$ range from 0.113 to 0.512 . For a $\lambda=2.5$, the average $\alpha$ is 0.307 , and the values for $\alpha$ range from 0.125 to 0.636 . These values are close to 0.5 . The same pattern 
shows up here: the higher the assumed coefficient for loss aversion $\lambda$, the higher is the estimate of $\alpha$.Again and in general loss aversion explains very well risky stock market return outcomes. There is still one discrepancy however, like previously. Next to the estimates of $\alpha$, in Table 7, is the starting value (SV) for each simulation. If this starting value is obeyed the model converges directly and quickly to the reported estimates of $\alpha$. If the starting value (SV) is higher than the one reported, then the program does not converge at first, and for higher values of $\alpha$ the program converges to estimates of $\alpha$ that are higher than +1 . It is not known why this anomaly is present. Otherwise diminishing sensitivity readily explains risky stock market return outcomes.

\section{Insert Table 7 (Appendix G)}

Table 8 departs from Table 4, in that the free parameter is $\lambda$. In the first case $\alpha=\sigma=$ 0.88, in conformity to Tversky and Kahneman (1992). And in the second case $\alpha=0.5$, and $\sigma=1$. For the first case the average value of $\lambda$ is 2.977 , and the values range between 2.252 and 4.269. And for the second case the average value of $\lambda$ is 3.921 , and the values range between 1.486 and 6.090. In both cases the loss aversion coefficient is higher than +1 as predicted by prospect theory. Finally, one pattern shows up: the more there are states of nature in an economy the higher is the estimated coefficient of loss aversion $\lambda$.

\section{Insert Table 8 (Appendix H)}

Hence, overall, the conclusion is still very strong that loss aversion explains quite well the stock market return dynamics.

\section{DISCUSSION}

There are four characteristics that need to be found in order to conclude that loss aversion explains stock market data. The first is having a reference point for valuation. This has been followed in the analysis since I took percentages: the reference is therefore zero. The second is probability weighting, and this was considered in the preceding section. The third is diminishing sensitivity. This is corroborated in Tables 3 and 7. The fourth requirement is that the coefficient of loss aversion for losses to be higher than the one for gains.

If there are gains the valuation function is of the following shape: $X^{\alpha}$, where $\alpha$ is the elasticity. Since $X$ is already in percent, then it should be interesting to find out whether the marginal effect, which is like a form of elasticity, obeys also to diminishing sensitivity, i.e. whether the marginal effect is also less than +1 . The definition of the elasticity and the marginal effect are:

$$
\text { elasticity }=\frac{\partial\left(X^{\alpha}\right)}{\partial X} \frac{x}{X^{\alpha}}=\alpha \Rightarrow \text { marginal effect }=\frac{\partial\left(X^{\alpha}\right)}{\partial X}=\alpha \frac{X^{\alpha}}{X}=\beta
$$

When evaluated at the means the marginal effect includes $E(X)$ instead of $X$ in the denominator, and $E\left(X^{\alpha}\right)$ instead of $X^{\alpha}$ in the numerator. The parametersare for $E(X)=0.133=13.3 \%$, and for $\sigma=0.201=20.1 \%$. A Taylor series expansion of $X^{\alpha}$ around $E(X)$ results in:

$X^{\alpha} \cong(E(X))^{\alpha}+(x-E(X)) * \alpha *(E(X))^{\alpha-1}+0.5 *(x-E(X))^{2} * \alpha *(\alpha-1) *(E(X))^{\alpha-2}$

Which implies that: 


$$
E\left(X^{\alpha}\right) \cong(E(X))^{\alpha}+0+0.5 * \sigma^{2} * \alpha *(\alpha-1) *(E(X))^{\alpha-2}
$$

The values for $\beta$, and the corresponding values of $\alpha$, are tabulated in Table 9. The values of $\alpha$ are taken from Tables 3 and 7 . The maximum $\beta$ is found to be 0.9797 , below one, and the minimum is positive and is equal to 0.556 , also less than +1 . The standard deviationis 0.125 , and the standard error is 0.021 . What is remarkable it is the average $\beta$, which equals 0.8983 , clearly close to the average estimate of 0.88 in Tversky and Kahneman (1992). Therefore the requirement that there should be diminishing sensitivity is obeyed extremely well.

\section{Insert Table 9 (Appendix I)}

\section{CONCLUSION}

Loss aversion is a key concept in behavioral finance. This paper tests whether loss aversion can explain stock market developments. There are three parameters to solve for. The first is the exponent of the valuation function of positive gains, which is expected to be less than one. The second is the exponent of the valuation function of negative losses, which is expected to be less or equal to +1 . The third parameter is the loss aversion factor, which is expected to be higher than +1.Two out of these three parameters must be pre-specified in order to solve for the remaining one by solving the non-linear certainty equivalence property of expected utility. The free parameter, which is estimated from the optimization process, conforms to expectations. When the two exponents of the piece-wise valuation function are set to be equal, and when the loss aversion coefficient is pre-specified, then the exponent turns out to be less than +1 , as expected by the theoretical construct of diminishing sensitivity. When the exponent of the valuation function of losses is set to be equal to +1 , and the loss aversion coefficient is prespecified, the parameter that is solved for is the exponent of the valuation function of gains, and it is estimated to be close to 0.5 , again satisfying the requirement of diminishing sensitivity. When the sensitivities are set to be equal to 0.88 , which is the literature's estimate, the parameter to be solved for is the loss aversion coefficient which is found to be consistently higher than +1 , and even higher than +2 . Finally, when the first exponent is set to be 0.5 and the second exponent to be +1 , the parameter that is solved for is again the loss aversion coefficient, which turns out to be higher than 2.5. Repeating the analysis with probability weighting does not materially affect the results. All this leads us to conclude that loss aversion is a sensible tool to explain stock market developments. This should enhance the acceptability of loss aversion as a paradigm.

\section{REFERENCES}

Abdellaoui, M. (2000). Parameter-free elicitation of utility and probability weighting functions. Management science, 46(11), 1497-1512.

Abdellaoui, M., Bleichrodt, H., \& 1'Haridon, O. (2008). A tractable method to measure utility and loss aversion under prospect theory. Journal of Risk and uncertainty, 36(3), 245.

Abdellaoui, M., Bleichrodt, H., \& Paraschiv, C. (2007). Loss aversion under prospect theory: A parameter-free measurement. Management Science, 53(10), 1659-1674. 
Akerlof, G. A., \& Shiller, R. (2009), Animal Spirits: How Human Psychology Drives the Economy, and Why It Matters for Global Capitalism, Princeton University Press, Princeton.

Angner, E. (2016). A Course in Behavioral Economics, $2^{\text {nd }}$ edition, Palgrave MacMillan.

Benartzi, S., \& Thaler, R. H. (1995). Myopic loss aversion and the equity premium puzzle. The quarterly journal of Economics, 110(1), 73-92.

Camerer, C. (2005). Three cheers—psychological, theoretical, empirical—for loss aversion. Journal of Marketing Research, 42(2), 129-133.

Camerer, C. F., \& Ho, T. H. (1994). Violations of the betweenness axiom and nonlinearity in probability. Journal of risk and uncertainty, 8(2), 167-196.

Camerer, C. F., Loewenstein, G., \& Rabin, M. (Eds.). (2011). Advances in Behavioral Economics, Princeton University Press, Princeton.

Fama, E. F. (1970). Efficient capital markets: A review of theory and empirical work, The Journal of Finance, 25(2), 383-417.

Fama, E. F. (1991). Efficient capital markets: II, The Journal of Finance, 46 (5), 1575-1617.

Fishburn, P. C., \& Kochenberger, G. A. (1979). Two-piece von Neumann-Morgenstern utility functions. Decision Sciences, 10(4), 503-518.

Foellmi, R., Jaeggi, A., \& Rosenblatt-Wisch, R. (2019). Loss aversion at the aggregate level across countries and its relation to economic fundamentals. Journal of Macroeconomics, 61, 103136.

Gal, D., \& Rucker, D. D. (2018). The loss of loss aversion: Will it loom larger than its gain?. Journal of Consumer Psychology, 28(3), 497-516.

Kahneman, D. (2011). Thinking, fast and slow. Macmillan.

Kahneman, D., \& Tversky, A. (Eds.) (2000). Choices, Values, and Frames, Princeton University Press, Cambridge.

Levy, M. (2010). Loss aversion and the price of risk. Quantitative Finance, 10(9), 1009-1022.

Malkiel, B. G. (1996). A Random Walk Down Wall Street, Norton: New York.

Markowitz, H. (1952). Portfolio selection, The Journal of Finance, 7(1), 77-91.

Novemsky, N., \& Kahneman, D. (2005). The boundaries of loss aversion. Journal of Marketing research, 42(2), 119-128. 
Paraschiv, C., \& L'Haridon, O. (2008). Aversion aux pertes: origine, composantes et implications marketing. Recherche et Applications en Marketing (French Edition), 23(2), 67-83.

Ross, S. A., Westerfield, R. W., \& Jaffe, J. (2002). Corporate Finance, McGraw Hill: New York.

Schmidt, U., \& Traub, S. (2002). An experimental test of loss aversion. Journal of risk and Uncertainty, 25(3), 233-249.

Shiller, R. (2000). Irrational Exuberance, Princeton University Press, Princeton.

Tovar, P. (2009). The effects of loss aversion on trade policy: Theory and evidence. Journal of International Economics, 78(1), 154-167.

Tversky, A., \& Kahneman, D. (1974). Judgment under uncertainty: Heuristics and biases, Science, 185(4157), 1124-1131.

Tversky, A., \& Kahneman, D. (1981). The framing of decisions and the psychology of choice, Science, 211(4481), 453-458.

Tversky, A., \& Kahneman, D. (1992). Advances in prospect theory: Cumulative representation of uncertainty", Journal of Risk and Uncertainty, 5(4), 297-323.

Wu, G., \& Gonzalez, R. (1996). Curvature of the probability weighting function. Management science, 42(12), 1676-1690.

\section{APPENDICES}

Appendix A: Table 1. Six different economies with similar means and standard deviations.

\begin{tabular}{|l|l|l|l|r|}
\hline $\begin{array}{c}\text { Econom } \\
\mathrm{y}\end{array}$ & $\begin{array}{c}\text { Individual } \\
\text { objective } \\
\text { probabilities }\end{array}$ & $\begin{array}{c}\text { Number } \\
\text { of states } \\
\text { of nature }\end{array}$ & \multicolumn{1}{|c|}{ Equally weighted outcomes } & $\begin{array}{r}\text { Mean and } \\
\text { Standard } \\
\text { deviation }\end{array}$ \\
\hline $\mathrm{A}$ & $1 / 2$ & 2 & $35 \%,-8 \%$ & 0.135 \\
$\mathrm{~B}$ & $1 / 3$ & 3 & $40 \%, 15 \%,-15 \%$ & 0.2150 \\
$\mathrm{C}$ & $1 / 4$ & 4 & $35 \%, 25 \%, 10 \%,-20 \%$ & 0.1333 \\
$\mathrm{D}$ & $1 / 5$ & 5 & $40 \%, 25 \%, 20 \%,-5 \%,-15 \%$ & 0.2248 \\
$\mathrm{E}$ & $1 / 6$ & 6 & $45 \%, 25 \%, 20 \%, 10 \%,-7 \%,-15 \%$ & 0.125 \\
$\mathrm{~F}$ & $1 / 7$ & 7 & $55 \%, 35 \%, 15 \%, 10 \%, 0 \%,-5 \%,-15 \%$ & 0.2077 \\
& & & & 0.1300 \\
\hline
\end{tabular}




\begin{tabular}{|l|l|l|l|l|}
\hline & & & 0.1300 \\
& & & & 0.2004 \\
& & & 0.1357 \\
& & & & 0.2247 \\
\hline
\end{tabular}

Appendix B: Table 2. List of the exponent $(\alpha)$ of the valuation functional form $U$, given the description of the economy.

$$
\begin{gathered}
U=X^{\alpha} \quad \text { if } X \geq 0 \\
U=-\lambda(-X)^{\alpha} \quad \text { if } X<0
\end{gathered}
$$

\begin{tabular}{|c|c|c|c|}
\hline & \multicolumn{3}{|c|}{$\lambda$ : loss aversion coefficient } \\
\hline Economy & 2 & 2.25 & 2.5 \\
\hline A & 0.77216 & 0.81686 & 0.85935 \\
B & 0.74559 & 0.81660 & 0.88718 \\
C & 0.69513 & 0.79003 & 0.89322 \\
D & 0.73002 & 0.78426 & 0.83741 \\
E & 0.68672 & 0.74141 & 0.79509 \\
F & 0.65185 & 0.69186 & 0.73091 \\
\hline average & 0.71358 & 0.77350 & 0.83386 \\
\hline
\end{tabular}

Appendix C: Table 3. List of the exponent $(\alpha)$ of the valuation functional form $U$, given the description of the economy, assuming linear loss aversion for losses.

$$
\begin{gathered}
U=X^{\alpha} \quad \text { if } X \geq 0 \\
U=-\lambda(-X) \quad \text { if } X<0
\end{gathered}
$$

\begin{tabular}{|c|c|c|c|c|c|c|}
\hline & \multicolumn{2}{|c|}{$\lambda=2$} & \multicolumn{2}{c|}{$\lambda=2.25$} & \multicolumn{2}{c|}{$\lambda=2.5$} \\
\hline Economy & $\alpha$ & SV & $\alpha$ & SV & $\alpha$ & SV \\
\hline A & 0.44491 & $<0.82$ & 0.46938 & $<0.82$ & 0.49736 & $<0.82$ \\
\hline B & 0.36016 & $<0.70$ & 0.38899 & $<0.70$ & 0.42336 & $<0.70$ \\
\hline C & 0.30435 & $<0.63$ & 0.33098 & $<0.63$ & 0.36248 & $<0.63$ \\
\hline D & 0.38174 & $<0.75$ & 0.40420 & $<0.74$ & 0.42975 & $<0.74$ \\
\hline E & 0.33722 & $<0.70$ & 0.35623 & $<0.70$ & 0.37736 & $<0.70$ \\
\hline F & 0.39439 & $<0.76$ & 0.41007 & $<0.77$ & 0.42704 & $<0.78$ \\
\hline average & 0.37046 & & 0.39331 & & 0.41956 & \\
\hline
\end{tabular}

SV stands for the starting value of $\alpha$ for the optimization. 
Appendix D: Table 4. List of the loss aversion coefficient $(\lambda)$ of the valuation functional form $U$, given the description of the economy.

\begin{tabular}{|c|c|c|}
\hline & $U=X^{0.88}$ if $X \geq 0$ & $U=X^{0.5}$ if $X \geq 0$ \\
Economy & $U=-\lambda(-X)^{0.88}$ if $X<0$ & $U=-\lambda(-X)$ if $X<0$ \\
\hline A & 2.6261 & 2.5217 \\
B & 2.2474 & 2.8996 \\
C & 2.4691 & 3.1405 \\
D & 2.7042 & 3.0250 \\
E & 2.9065 & 3.4757 \\
F & 3.5166 & 3.3610 \\
\hline average & 2.7450 & 3.0706 \\
\hline
\end{tabular}

Appendix E: Table 5. Probability weighting.

\begin{tabular}{|c|c|c|c|}
\hline Economy & Objective probability & $\begin{array}{c}\text { Subjective probability } \\
\text { for gains }\end{array}$ & $\begin{array}{c}\text { Subjective probability } \\
\text { for losses }\end{array}$ \\
\hline A & $1 / 2=0.50$ & 0.420639 & 0.453988 \\
B & $1 / 3=0.333333$ & 0.335052 & 0.349373 \\
C & $1 / 4=0.25$ & 0.290743 & 0.293519 \\
D & $1 / 5=0.20$ & 0.260763 & 0.257025 \\
E & $1 / 6=0.166666$ & 0.238761 & 0.230701 \\
F & $1 / 7=0.142857$ & 0.221622 & 0.210539 \\
\hline
\end{tabular}

Appendix F: Table 6. List of the exponent $(\alpha)$ of the valuation functional form $U$, given the description of the economy, and with probability weighting.

$$
\begin{gathered}
U=X^{\alpha} \quad \text { if } X \geq 0 \\
U=-\lambda(-X)^{\alpha} \quad \text { if } X<0
\end{gathered}
$$

\begin{tabular}{|c|c|c|c|}
\hline & \multicolumn{3}{|c|}{$\lambda$ : loss aversion coefficient } \\
\hline Economy & 2 & 2.25 & 2.5 \\
\hline A & 0.83600 & 0.79723 & 0.92135 \\
B & 0.76597 & 0.83996 & 0.91330 \\
C & 0.63283 & 0.73433 & 0.84518 \\
D & 0.65265 & 0.71175 & 0.76935 \\
E & 0.55718 & 0.61930 & 0.67992 \\
F & 0.50118 & 0.54859 & 0.59450 \\
\hline average & 0.65764 & 0.70853 & 0.78727 \\
\hline
\end{tabular}


Appendix G: Table 7. List of the exponent $(\alpha)$ of the valuation functional form $U$, given the description of the economy, assuming linear loss aversion for losses, and with probability weighting.

$$
\begin{gathered}
U=X^{\alpha} \quad \text { if } X \geq 0 \\
U=-\lambda(-X) \quad \text { if } X<0
\end{gathered}
$$

\begin{tabular}{|c|c|c|c|c|c|c|}
\hline & \multicolumn{2}{|c|}{$\lambda=2$} & \multicolumn{2}{c|}{$\lambda=2.25$} & \multicolumn{2}{c|}{$\lambda=2.5$} \\
\hline Economy & $\alpha$ & SV & $\alpha$ & SV & $\alpha$ & SV \\
\hline A & 0.55708 & $<0.90$ & 0.59227 & $<0.90$ & 0.63603 & $<0.90$ \\
\hline B & 0.36366 & $<0.70$ & 0.39496 & $<0.70$ & 0.43308 & $<0.70$ \\
\hline C & 0.19710 & $<0.54$ & 0.21819 & $<0.54$ & 0.24208 & $<0.54$ \\
\hline D & 0.22174 & $<0.60$ & 0.23789 & $<0.60$ & 0.25549 & $<0.60$ \\
\hline E & 0.10121 & $<0.49$ & 0.11284 & $<0.49$ & 0.12520 & $<0.49$ \\
\hline F & 0.13185 & $<0.47$ & 0.14168 & $<0.47$ & 0.15200 & $<0.47$ \\
\hline average & 0.26211 & & 0.28297 & & 0.30731 & \\
\hline
\end{tabular}

SV stands for the starting value of $\alpha$ for the optimization.

Appendix H: Table 8. List of the loss aversion coefficient $(\lambda)$ of the valuation functional form $U$, given the description of the economy, and with probability weighting.

\begin{tabular}{|c|c|c|}
\hline Economy & $\begin{array}{c}U=X^{0.88} \text { if } X \geq 0 \\
U=-\lambda(-X)^{0.88} \text { if } X<0\end{array}$ & $\begin{array}{c}U=X^{0.5} \text { if } X \geq 0 \\
U=-\lambda(-X) \text { if } X<0\end{array}$ \\
\hline A & 2.2516 & 1.4846 \\
B & 2.3861 & 2.8175 \\
C & 2.5746 & 3.6519 \\
D & 2.9994 & 4.2211 \\
E & 3.3786 & 5.2585 \\
F & 4.2685 & 6.0904 \\
\hline average & 2.9765 & 3.9207 \\
\hline
\end{tabular}

Appendix I: Table 9. Estimates of $\beta=\frac{\partial y}{\partial x}=\frac{\alpha \bar{Y}}{\bar{X}}$ where $=X^{\alpha}, \bar{X}=13.3 \%, \sigma=0.201$, and

$$
\bar{Y} \cong 0.133^{\alpha}+0.5 *\left(0.201^{2}\right) * \alpha *(\alpha-1) *\left(0.133^{\wedge}(\alpha-2)\right)
$$

\begin{tabular}{|c|c|c|c|c|c|c|c|c|c|c|c|}
\hline$\alpha$ & $\beta$ & $\alpha$ & $\beta$ & $\alpha$ & $\beta$ & $\alpha$ & $\beta$ & $\alpha$ & $\beta$ & $\alpha$ & $\beta$ \\
\hline 0.4449 & 0.9789 & 0.4694 & 0.9797 & 0.4974 & 0.9796 & 0.5571 & 0.9778 & 0.5923 & 0.9764 & 0.6360 & 0.9751 \\
\hline 0.3602 & 0.9649 & 0.3890 & 0.9722 & 0.4234 & 0.9772 & 0.3637 & 0.9659 & 0.3950 & 0.9733 & 0.4331 & 0.9781 \\
\hline 0.3044 & 0.9390 & 0.3310 & 0.9536 & 0.3625 & 0.9656 & 0.1971 & 0.8158 & 0.2182 & 0.8506 & 0.2421 & 0.8829 \\
\hline 0.3817 & 0.9706 & 0.4042 & 0.9748 & 0.4298 & 0.9778 & 0.2217 & 0.8558 & 0.2379 & 0.8777 & 0.2555 & 0.8981 \\
\hline 0.3372 & 0.9564 & 0.3562 & 0.9636 & 0.3774 & 0.9696 & 0.1012 & 0.5560 & 0.1128 & 0.5984 & 0.1252 & 0.6398 \\
\hline 0.3944 & 0.9732 & 0.4101 & 0.9757 & 0.4270 & 0.9776 & 0.1319 & 0.6605 & 0.1417 & 0.6893 & 0.1520 & 0.7172 \\
\hline
\end{tabular}

\begin{tabular}{|c|c|c|}
\hline & $\alpha$ & $\beta$ \\
\hline Maximum & 0.63603 & 0.979675 \\
\hline
\end{tabular}




\begin{tabular}{|l|l|l|}
\hline Minimum & 0.10121 & 0.555984 \\
\hline Average & 0.33929 & 0.898294 \\
\hline $\begin{array}{l}\text { Standard } \\
\text { deviation }\end{array}$ & 0.13679 & 0.124955 \\
\hline $\begin{array}{l}\text { Standard } \\
\text { error }\end{array}$ & 0.02280 & 0.020826 \\
\hline
\end{tabular}

\section{Copyrights}

Copyright for this article is retained by the author(s), with first publication rights granted to the journal. This is an open-access article distributed under the terms and conditions of the Creative Commons Attribution license (http://creativecommons.org/licenses/by/4.0/) 